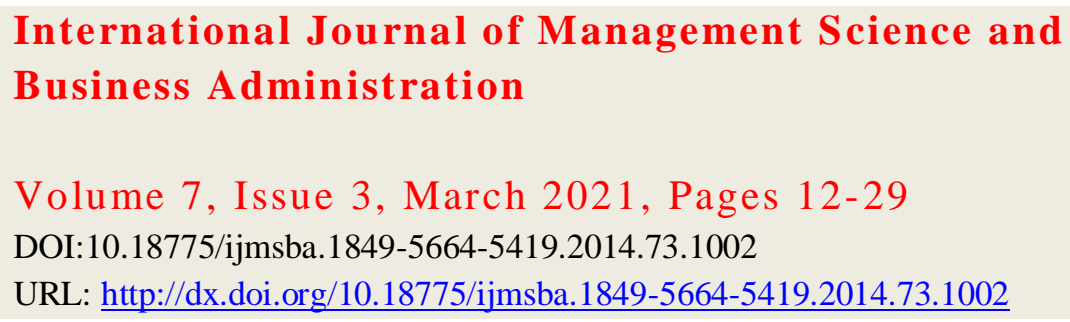

\title{
Forming the Bargaining Win-Win-Win Papakonstantinidis Tripartite Focal Points Analysis of the Bibliography
}

\author{
Leonidas A. Papakonstantinidis \\ University of Peloponnese, GR, Academician (IMA Academy, RU) Honorary Professor UBL University, \\ Indonesia, Visiting Professor IIIT University Bhagalpur, India
}

\begin{abstract}
Focal points, in a period that people are reviewing their priorities, in a more social direction due to the pandemic, as a global threat and catastrophe, are examined in this work, under the prism of the win-win-win papakonstantinidis perception, closer to the tripartite global concept. Identity, social justice, and the community spirit seem to be the new-day priorities in a "pandemic period", under a win-win-win perception: the last one is analyzed through the sequence toward the limit $\ln 2=0,693$ and the disagreement point in a bargain. Finally, its philosophical perspective is analyzed through the tripartite thesis.
\end{abstract}

Research on pandemic "behavior" is provided at the end of this work.

Keywords: Focal point, Win-Win-Win situation, Pandemic situation, Absence of communication, Behaviour

\section{Part 1}

\subsection{Introduction}

"The concepts of 'focal point' and 'salience' have become part of the tool-kit of game theory. Despite that, focal points have never been integrated into the formal structure of the theory. Although theorists often invoke notions of salience when dealing with otherwise intractable problems of equilibrium selection, they do so in a spirit of faute de mieux" (Gold and Sugden (2006)).

In game theory, a focal point (or Schelling point) is a solution that people tend to choose by default in the absence of communication.

Focal points presuppose a near-default behavior in a near-default culture in a bipolar world. A Bipolar behavior, at least in the western world, is compatible with a particular grosso modo behavior in the absence of communication.

But what happens in the case of a triploid behavior, of the form "what will I gain from the negotiation, what will the other negotiator gain, what will the community in which we negotiate gain?".

The next question is: "how ready is today's society to accept the tripartite of negotiation?"

Is it possible people to be coordinated on this idea?

The reason is that people can be coordinated - without prior communication - to a different level of a threefold direction of individual satisfaction (I win), social justice (you win) and community integration (we win) because they are driven by two instincts, namely survival and self-adaptability, coming from survival.

The second and most important reason is that today: a. the conditions for a tripartite reaction have matured and people are more willing to accept it. 
b. people are reviewing their priorities, in a more social direction: the pandemic, as a global threat and catastrophe, unites people from different classes, incomes, religions, philosophical references-see "research on pandemic priorities".

The concept of focal points was introduced by the American economist Thomas Schelling in his book The Strategy of Conflict (1960). Schelling states that "people can often concert their intentions or expectations with others if each knows that the other is trying to do the same".

\subsection{The Dilemma}

The dilemma of how two people can coordinate on the same strategy is in the centre of focal points Firms, nations, and individuals frequently face situations where coordination is among the most desirable outcomes, and sometimes such coordination is achieved. However, traditional game theory offers little guidance on how to systematically predict when coordination will occur.

Two different streams of literature have addressed this problem. One stream, originating with Schelling (1960), examines behavior in pure matching games in which players receive a fixed positive payoff whenever their strategy selections match and a payoff of zero otherwise.

The existence of the focal point is first demonstrated by Schelling with a series of questions. The most famous one is the New York City question: if you are to meet a stranger in New York City, Schelling's informal experiments have been replicated under controlled conditions with monetary incentives by Mehta.

Since the classic work of Schelling, the notion of a focal point has been widely applied to explain coordinated behavior. The model characterizes situations when Nash equilibria are likely to be played, even in a one-shot interaction, and predicts which equilibrium will obtain in games containing more than one. It identifies other circumstances in which a non-equilibrium outcome will predominate. Finally, the theory specifies when a player is likely to select a strategy based solely on consideration of her own payoffs, and when and why the same player will be prompted to act strategically. Experimental results are presented that test the predictions of the model.

\subsection{Utility Function- Marginal Rate of Substitution}

As we see, a stream, derived from Schelling (1960), examines behavior in pure matching games in which players receive a consistent positive reward whenever their strategy choices match and a zero return, otherwise.

Imagine now, a tripartite negotiation, in which the focal points are more than one Imagine an ordinary Man, who will have to take a decision based on either his individual earnings or his social environment.

In fact, individual balances between his will and his social perspective, between pure individual payoff and the social, religious self-restraint.

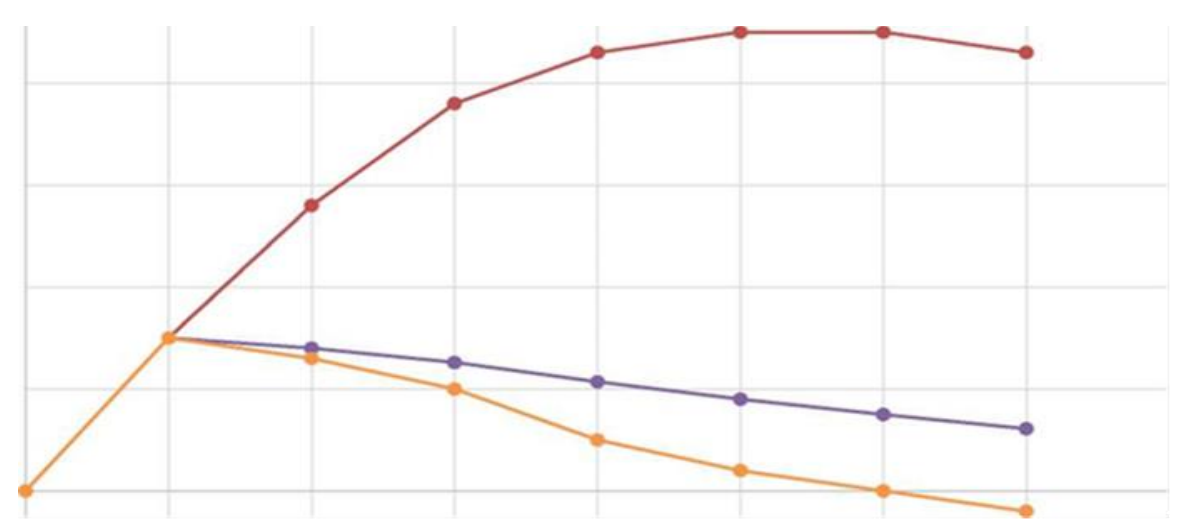

Figure 1: Utility function $\mathrm{f}(\mathrm{U})$ 


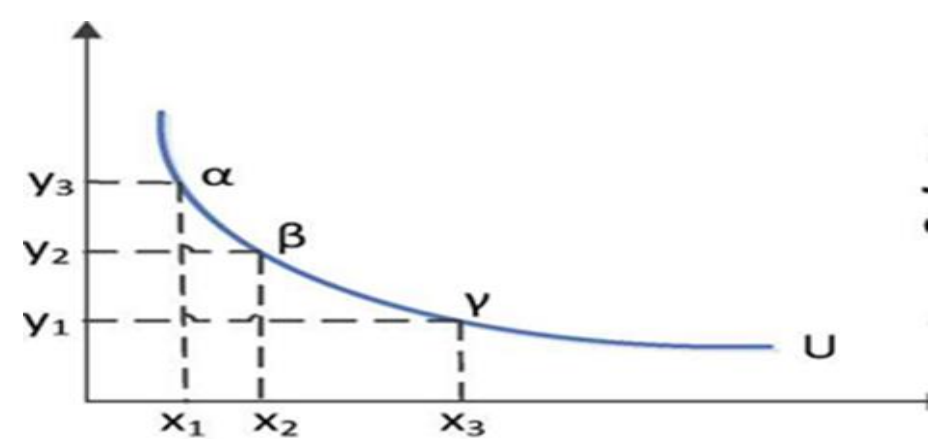

Figure 3: The win-win-win papakonstantinidis approach $-\frac{d y}{d x}=M R S=\frac{P_{x}}{P_{y}} \quad$ Equilibrium-E

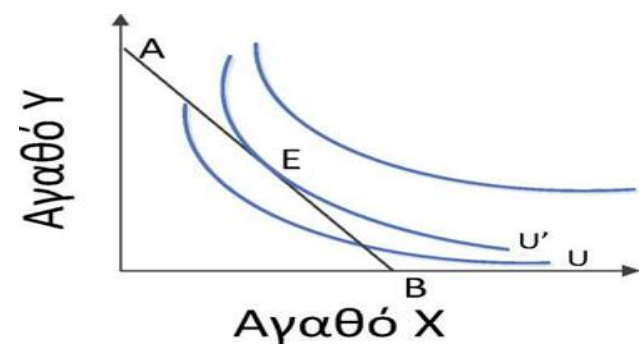

Figure 4: The win-win-win papakonstantinidis approach

In this case, people have to choose an alternative covered the three conditions in each bargain: individual benefit (I win-Ia), legal benefit (you win-Ib) and socio-community benefit (we win-Ic) as below.

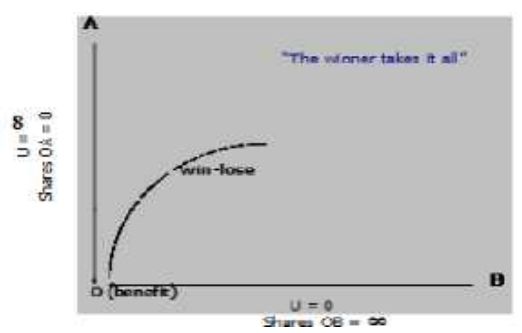

Figure 5: Individual benefit (I win-Ia)

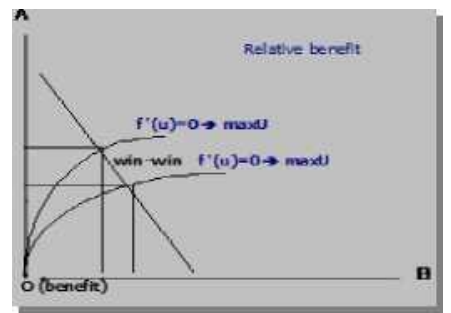

Figure 6: Legal benefit (you win-Ib)

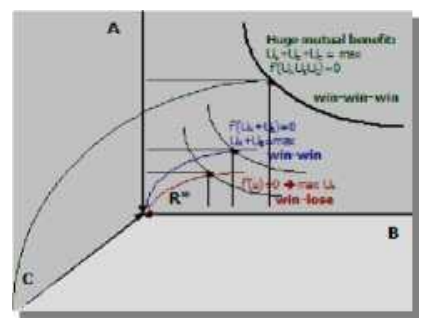

Figure 7: Socio-community benefit (we win-Ic) 
The reason for this is that the indifferent curves in a 3-D space-see the Ic figure- are more complicated and that the equilibrium point emergences in this tripartite question.

\subsection{Tripartite View}

\subsubsection{Game}

Two different streams of literature have addressed this problem. One stream, originating with Schelling (1960), examines behavior in pure matching games in which players receive a fixed positive payoff whenever their strategy selections match and a payoff of zero otherwise. A simple example of such a game is one where players each choose between strategies labeled.

Heads and Tails, receive $\$ 1$ if their choices match (i.e., are HH or TT), and receive $\$ 0$ otherwise. A large body of experimental evidence demonstrates that people do much better than chance at coordinating in these types of games. Specifically, it appears that the strategy Heads comes immediately to mind more often than Tails, resulting in the focal point outcome Heads-Heads.

Schelling (1960) attributed this better-than-chance performance to one of the strategy options appearing more salient in the minds of the players because of commonly shared culture or psychology. The shared salience of one of the strategy labels results in that outcome being perceived as a focal point. Traditional game theory cannot explain the coordination observed in symmetric matching games since the theory gives no special status to a label of Head Tails.

Focal points can also have real-life applications. For example, imagine two bicycles headed towards each other and in danger of crashing. Avoiding collision becomes a coordination game where each player's winning choice depends on the other player's choice. Each player, in this case, has the choice to go straight, swerve to the left or swerve to the right. Both players want to avoid crashing, but neither knows what the other will do. In this case, the decision to swerve right can serve as a focal point which leads to the winning right-right outcome. It seems a natural focal point in places using right-hand traffic. This idea of anti-coordination game is also apparent in the game of chicken, which involves two cars racing toward each other on a collision course and in which the driver who first decides to swerve is seen as a coward, while no driver swerving results in a fatal collision for both.

Table 1: A win-win-win papakonstantinidis trial-and-error adjustment processes

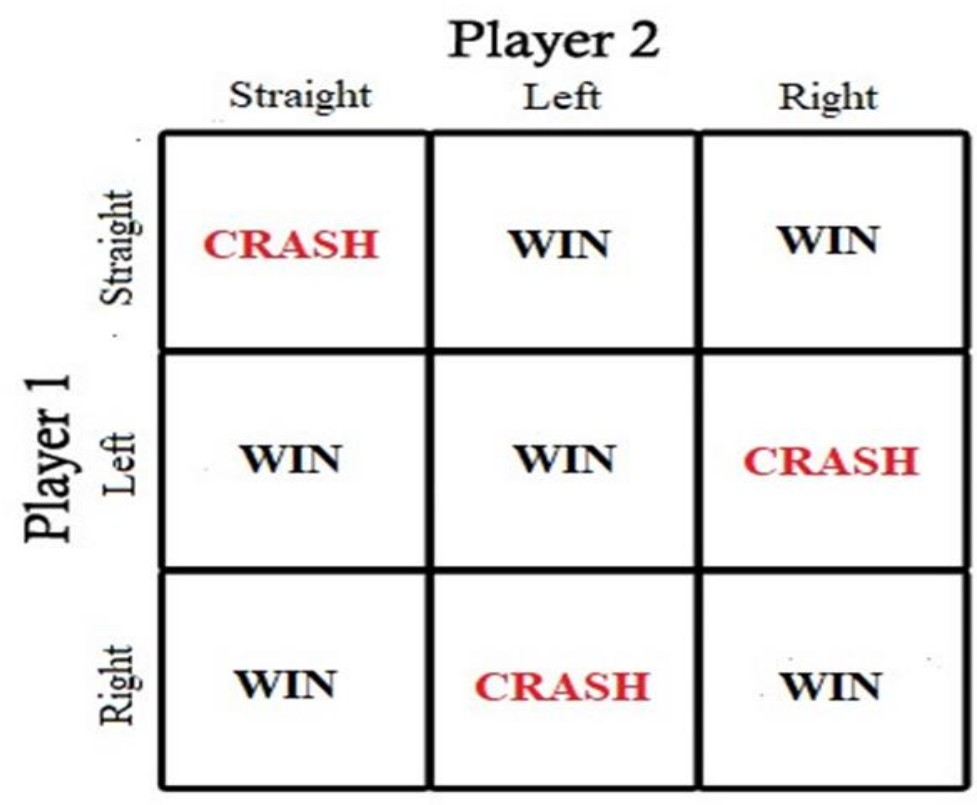

The basic idea here is that the win-win-win papakonstantinidis equilibrium is achieved gradually with continuous approaches. This equilibrium is approached by the limit of the

$$
\left(1+\frac{1}{n}\right)^{n} \text { sequence, as } \mathrm{n}>\infty
$$


A. Limit of a sequence's approach: The hlp 3-ple proposed equilibrium

$3^{\mathrm{RD}}$ approach: the 3 sequences, converging in: $\phi \leq h l p<e$

The "win-win-win concept" :Sensitization Process: terms of a continuous sequence $u_{n}, .$. with.. $\lim _{n \rightarrow \infty} u_{n}=. h_{l p}^{*} .=$ community..win..- The...end..of ..senitization..process

We suppose that $\phi, e, \pi$ form a NEW sequence $W_{n \text { converging in }} h l p$

$\varphi$, e, $\pi$ relationship's manipulation

We can take the $\varphi . e, \pi$ interactive relations in more than one ways:

$\left(\begin{array}{l}n \\ k\end{array}\right)=\frac{n !}{k !(n-k) !}=\frac{(n(n-1 . .) \ldots . .(n-k-1)}{k(k-1 \ldots 1)}=\frac{3 * 2 * 1}{2 * 1(3-1)(3-2)}=3 \quad$ ways for $\phi, e, \pi$ combination

Taking into account the three mathematical constants $(\pi, \varphi, \mathrm{e})$, as the limits of $\left(u_{n}, . . v_{n}, . . z_{n}\right)$ i.e $\lim _{n \rightarrow \infty} .\left(u_{n}, . . v_{n}, . . z_{n}\right)$, then it is easy to manipulate their combination One of these math combinations seems to be $\phi: \frac{e}{\pi}$ $\frac{e}{\pi}=\frac{2,718}{3,14}=\frac{2,71}{3,14}=0,8569 . .=\omega$

$\frac{\phi}{\omega}=\frac{1,618 \ldots}{0,8569}=1,888 \ldots$

Even,

$\phi: \frac{e}{\pi}=\left(\frac{\phi}{\frac{e}{\pi}}\right)=\left(\frac{\frac{\phi}{e}}{\frac{e}{\pi}}\right)=\frac{\phi \pi}{e}=\left(\frac{1,618 * 3,14159}{2,7182818}\right)=\frac{5,083092}{2,7182818} \approx 1,888 .$.

$\lim _{n \rightarrow \infty} F_{n}=\phi \leq h l p=1,888 \ldots \prec \lim \left(1+\frac{1}{n}\right)^{n}=e, \ldots \ldots$

Table 2: The intermediate Sequence: The hlp eui-harmony point-1.888.

The intermediate sequence $g(x)$ between two sequences:

Suppose that $f(x) \leq g(x) \leq h(x)$.. in the area of $x_{0}$

$\lim _{\text {If }} f(x)=\lim _{x \rightarrow x_{0}} h(x)=L \in \mathbb{R}$ 


Then $\lim _{x \rightarrow x_{0}} g(x)=L$
$\begin{aligned} & \ln 2 \prec \phi \prec \ell i m u_{n} \leq \lim _{n \rightarrow \infty} v_{n} \leq \lim _{n \rightarrow \infty} z_{n} \prec e \\ & \ln _{n \leftarrow \infty} \approx \frac{1}{n}+\frac{1}{n+1}+\ldots \frac{1}{2 n-1} \prec \phi \leq \lim _{n \rightarrow \infty}\left(\frac{\phi \pi}{e}\right) \approx 1,888 . . \leq \frac{1}{n}+\frac{1}{n+1}+. . \prec\left(1+\frac{1}{n}\right)^{n} \approx e\end{aligned}$

The 3-win Lemma

if .. for..the..sequences.. $u_{n}, . . v_{n}, \ldots z_{n}, \ldots . n=1, . .2, . . n$

we..have,..that..u $u_{n} \prec v_{n} \prec z_{n}, \ldots$ for..all..n..and..that..they..are..all..converging,..i.e

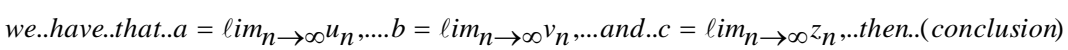

we..will..have.. $\lim _{n \rightarrow \infty} u_{n} \leq \lim _{n \rightarrow \infty} v_{n} \leq \lim _{n \rightarrow \infty} z_{n}, \ldots . i . e, \ldots . . a \leq b \leq c$

we.' ll..use..the..ln.2,..to..start..with

If ..c..is..the.. im $_{n \rightarrow \infty} .$. of ... $z_{n}=\left(1+\frac{1}{n}+\frac{1}{n+1}+\frac{1}{n+2}+\ldots \frac{1}{2 n}\right)=\left(1+\frac{1}{n}\right)^{n} \leq e \approx 2,7182816 \ldots$

If ....a...is..the.. $\lim _{n \rightarrow 0} \ldots$ of ... $u_{n}=\left(\frac{1}{n}+\frac{1}{n+1}+\ldots \frac{1}{2 n-1}\right) \geq \ln 2$

then,

$$
\ell n 2 \leq u_{n}, . . v_{n}, \ldots z_{n} \leq e
$$

We will now show that the sequence

$$
u_{n}=\frac{1}{n+1}+\frac{1}{n+2}+\ldots+\frac{1}{2 n}, \ldots n=1, . .2, . .
$$

converges and we have:

$$
\lim _{n \rightarrow \infty}\left(\frac{1}{n+1}+\frac{1}{n+2}+\ldots .+\frac{1}{2 n}\right)=\log _{e} 2=\ln 2
$$

Statement (Papakonstantinidis, 2018)

The sensitization process-which is the core of this Work -may be formulated by the three (3) world constants, as limits of $u_{n}, v_{n}, z_{n:} \phi, e, \pi$ 
$W_{n}, .$. so..that.. $\lim _{n \rightarrow \infty} W_{n}=h_{l p}^{*}=1,888 .$. such that ${ }^{1}$ :

$\ln 2 \prec \phi=1,618 . . \leq h l p=1,888 . . \leq e=2,7182818$

MeAsurement: DEViation \% from the $h l p_{\text {suggested Equilibrium }}$

The win-win-win papakonstantinidis model is, thus, the limit-up of a continuous sensitization procedure, at any (A-B) bargainers AND Community "C" symbolized by the three sequences', i.e.

$u_{n} \ldots$...for..the..BARGAINER....A

$\mathrm{v}_{\mathrm{n}}$....for...the..BARGA INER...B

$\mathrm{z}_{\mathrm{n}}$....for...the...COMMUNITY, AS...THE...THIRD...B ARGAINER

Indeed, you can imagine the successive steps towards sensitization as a series of sequence terms that converges to a limit.

The boundaries of these sequences, since they represent "sensitization levels", also form a new sequence $W_{n}$ and let $a$ a real number:

$$
\begin{gathered}
W_{n}, . . \text { with. } \lim _{n \rightarrow \infty} W_{n}=h l p \\
\left|W_{n}-a\right| \prec \varepsilon \\
\text { and } \\
\varepsilon \succ 0
\end{gathered}
$$

$W_{n}$ "sensitization sequence" converges at some point to the ideal limit -up ( the Angels' society) then all three limits of the $u_{n} \cdot v_{n}, z_{n}$ sequences $a, b$ and the community, $C$, respectively forming a new-unique sequence, which converges in a new

$$
h l p
$$

Welfare can be measured, as the deviation from $h l p$ suggested Equilibrium.

Tending toward an ideal (angels) situation, i.e the limit of the sensitization process, the win-win-win papakonstantinidis model is the limit-up of a continuous sensitization procedure, at any (A-B) bargainers symbolized by the three sequences', i.e.

$$
\lim _{n \rightarrow \infty} u_{n} \leq \lim _{n \rightarrow \infty} v_{n} \leq \lim _{n \leftarrow \infty} z_{n}
$$

In their limit, we have:

$$
\lim _{n \rightarrow \infty} u_{n}=\lim _{n \rightarrow \infty} v_{n}=\lim _{n \rightarrow \infty} z_{n}=\lim _{n \rightarrow \infty} W_{n}=1,888
$$


Indeed, you can imagine the successive steps towards sensitization as a series of sequence terms that converges to a limit.

The boundaries of these sequences, since they represent "sensitization levels", also form a new "Win" sequence We prove that this new sequence consists of their limits as "sensitization sequences" converges to the ideal limit -up (the perfect society, or the society of angels) then all three limits of the $u_{n} \cdot v_{n}, z_{n}$ sequences $a, b$ and the community, C, respectively forming a new-unique sequence, which converges in a new L limit.

Social bargaining in terms of disagreement 3-ple equilibrium

Ideal situation-the Angels' Moment

If $\mathrm{u}(\mathrm{x})=\mathrm{utility}$ from agreement and $\mathrm{u}(\mathrm{d}) \mathrm{utility}$ from disagreement and $\mathrm{t}=$ threat point. Then,

$$
\begin{aligned}
& u(x)-u\left(d_{1}\right)=\max \quad u\left(d_{1}\right)=0 \\
& v(y)-v\left(d_{2}\right)=\max \quad v\left(d_{2}\right)=0 \\
& C(z)-C\left(d_{3}\right)=\text { m.ax } \Leftrightarrow C\left(d_{3}\right)=0 \text { the Angels moment }
\end{aligned}
$$

The maximum profit for the society is

$$
\operatorname{m\alpha x}\left(u(x)-u\left(d_{1}\right)\right)\left(v(y)-v\left(d_{2}\right)\right)\left(C(z)-C\left(d_{3}\right)\right)
$$

Or, in threat terms:

$$
\max (u(x)-u(t))(v(y)-v(t))(C(z)-C(t))
$$

\section{Angels'. Society}

$$
\begin{aligned}
& M A X . .\left(u_{1}-t_{1}\right)\left(u_{2}-t_{2}\right)\left(u_{3}-t_{3}\right) \rightarrow\left[\left(u_{1}-t_{1}\right)\left(u_{2}-t_{2}\right)\left(u_{3}-t_{3}\right)\right]^{\prime}=0 \\
& \left(u_{1}-t_{1}\right)=M A X \\
& \left(u_{2}-t_{2}\right)=M A X \\
& \left(u_{3}-t_{3}\right)=M A X \\
& u_{i}: \text { utility.ex.pectation } \\
& t: \text {.the..value.the..players..can.ex.pect.to..recieve } \\
& \text { if.negotiation..break..down } \\
& t_{1} \rightarrow 0 \\
& t_{2} \rightarrow 0 \\
& t_{3} \rightarrow 0
\end{aligned}
$$


$>$ In a poetic expression, people have to set higher goals, in every interaction - negotiation so they can express their disagreement, at some point or threat point of stopping the negotiation.

$>\quad$ in an even more poetic expression, people must re-start dreaming of a better life again - one of the signs of globalization is to level everything for instant euphoria.

$>$ but so have people stopped dreaming ... Relationships, expectations, products and even lasting products (furniture-kitchens etc) and even the heads of state and government and relationships between them have all become instant (1).

$>$ The deep wound of globalization is the conversion of everything from constant to instant

$>$ People have to accept this "instant point", without history, future, and without dreams Ignatius Ramonet supports - and not unfairly - "...the past - present and the future has been squeezed into the instant now, the supreme moment of history ...... all made by the wish factory. "- 1000 cold "NO" for an emotional "YES" Leo Buskaglia.

$>$ Of course, every citizen has (at least theoretically the right of veto, a veto.

$$
\begin{aligned}
& \forall \mathrm{u}_{\mathrm{i}} \in \mathrm{S}_{\mathrm{i}} .\left(\mathrm{u}_{\mathrm{i}}-\mathrm{t}_{\mathrm{i}}\right), \exists \mathrm{t}_{\mathrm{i}}^{*} \text {, so..that.... }\left(\mathrm{u}_{1}-\mathrm{t}_{1}\right)<\left(\mathrm{u}_{2}-\mathrm{t}_{2}\right)<\ldots<\left(\mathrm{u}_{\mathrm{i}}-\mathrm{t}_{\mathrm{i}}^{*}\right) \\
& \mathrm{t}=\text { veto, or..democracy..perception }
\end{aligned}
$$

Papakonstantinidis 2019

The more sensitized is someone to a stimulus (eg environment) as "less objections" (less friction) will have to those who formulate development policies, which means that the differences between the level of satisfaction (utility function) and the disagreement point (d, disagreement point, or threat point, are gradually smoothed out. The degree of satisfaction increases as the point of objection increases gradually

$>$ The difference between cold rational and sensitized behavior and their mix to maximize the expected benefit to each and every one as he / she perceives determines the level of culture of a particular - local, basic society

$>$ The social predisposition of Humans makes the above relationship possible and the aim is to minimize the absolute difference between cold rationality and sensitized behavior: For example, protecting the natural environment.

$>$ It does not matter if we lose..1000 logical NO to an emotional YES... his life is endless .. always a winner

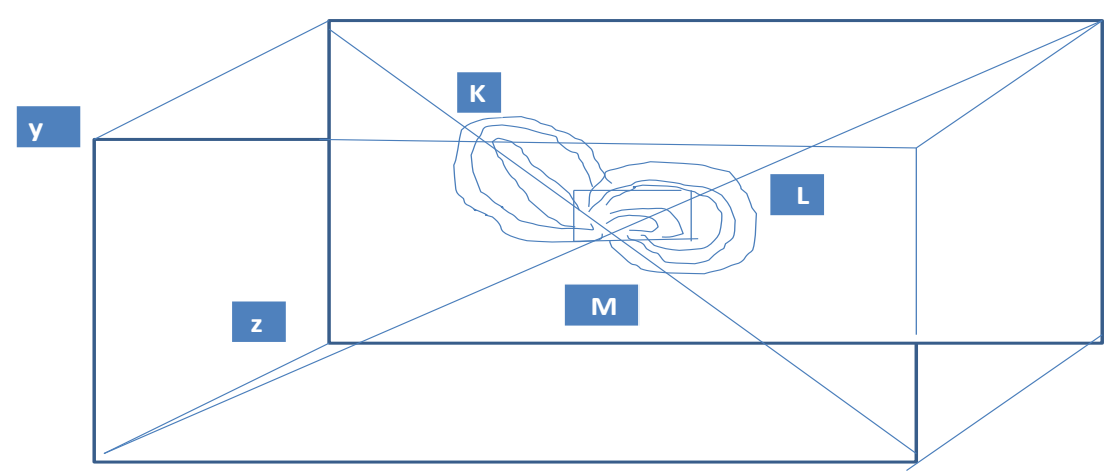

Figure 8: The step-by-step win-win-win approach in a 3-D space 
The step-by-step win-win-win approach in a 3-D space by the trial-and-error adjustment processes is as the above figure.

\section{PART II: Tripartite perception}

\subsection{Introduction}

Dynamic capability is rooted in the resource-based view theory of the organization (Barney, 1991; Eisenhardt and Martin, In this section we set the basic philosophical structure of the CONCEPT correspondence of 1-1 with the trimerization of the soul (Socrates, Plato-Religions-Psychology) i.e. the accounting, the thymoid-the volitional- and the spiritual Analyzing the tripartite thinking in one person that is, how will I win(accounting), how will the other negotiator win (voluntary) how will the community in which we negotiate win (spiritual), we observe the absolute soul-bargain identity, in the broad sense of exchange.

We argue that our world is structured in tripartite rather than in the bipolar system of the form $0-1$, or black and white ... We argue that a society would be much better if its actions corresponded to the three parts of the soul (psyche) This separation occupies the 4th chapter of Plato's State while most Religions refer to the trinity.

The win-win-win is not just an economic or mathematical model It is more a way of thinking and life to promote our thinking socially It is a way to be socially active, in the community It is a way to look more closely at the needs of others It is necessary to learn to offer beyond outdated individualism and individual pursuit.

The win-win-win tries to bring us back to the indivisibility of human thought and human life further away from the separate and individualism. The problems that humanity is currently experiencing (pandemic, extreme weather events, wars ...) require a new view beyond personal strategies We need a new "brave lie" according to Socrates (414b-415d).

[When Socrates, in "The State", reaches the point of arranging the organization of his ideal city, his interlocutor asks him how his citizens will be persuaded to observe the hierarchy he has set, without which, always according to Plato of course, justice is not possible. And then Socrates replies that a "brave lie" must be told which is believable by all. The word "lie" has two parts to it. The first is that all citizens were born from the same mother, from the earth, that is, that they are indigenous, the second is that their place in the city was defined by the gods.

True, it is strange to hear someone like Socrates, who sacrificed his life for the truth, to base his ideal state on a lie, albeit a brave one. Not so strange, however, if you look at the landscape of history and find that no society could ever be formed without a common belief in some "brave lie" - what postmodernists would call "narrative". The French Revolution had its own, that all people have equal rights, the Russian had its own, that the classes will be abolished. Economic liberalism is based on the brave lie of a self-regulating market that drives the global trading party on the path to prosperity].

There are phenomena that cannot be explained except by their result. We cannot prove - beyond the historical references and the "focal points" analysed here - the validity of tripartite thought, unless one compares where the one leads in and where the other leads in.

Bipolar thinking has led to unbridled individualism, unbridled rationalism in calculation, pandemic wars to environmental degradation, precisely because no one gives in. Recognizing the other negotiator's right and recognizing responsibility for the natural environment are two huge issues through which the importance of tripartite and the usefulness of the winwin-win papakonstantinidis are arisen.

We look below at typical cases of tripartite conception and the corresponding perception that is in people's minds, even in the form of expectation at typical cases of tripartite conception and the corresponding perception that is in people's minds, even in the form of expectation.

Religious 


\section{OOO}

According to Plato, the soul consists of three parts:

LOGIC, THYME (OR ANGER) AND DESIRE

1. LOGIC refers to the logical functions of man.

2. THYMOIDS refers to his emotional world (ie in the field of religious faith, ethics, emotions, ideologies, courage, virtue, hope, anger. Freedom, justice, etc. and this derives the strength human's.

3. THE DESIRE that concerns his wishes.

So to describe the form of the Soul, Plato makes his own "myth": the myth of the chariot. The reversal of Eros from the sphere of common pleasure to the view of beauty is achieved by the presentation of the inner forces of the soul:

Accounting, temporal or volitional and desirable.

The haircut of the soul is presented as a chariot drawn by two horses and led by a driver. The driver is the accounting, the mind, the two horses are the temporal (voluntary) and the desirable. This complex is unified and indivisible and it is up to the driver to master the horses so that there is harmony.

The Mind begins and protects.

The thymic obeys and accompanies with the mind, so that it can tame what is desired. Then the Soul enjoys harmony. Although both of these parts are animal they differ from each other, both functionally and evaluatively. This is evident from the fact that the temper, although animal and speechless as the desirable, willingly obeys the accounting (Iniocho) and acts as his accomplice for the subjugation of the desirable and for the restraint of the chariot of the human soul.

But because the reasons and the tricks with which the accounting of the ancient Greek held his temper were products of the functions of logic and therefore represented the hitherto unknown to other humanity-abstract concepts (such as freedom, logic, virtue, democracy, bravery, state, etc.) these reasons and these calls strengthened and strengthened in a unique way the strength of his temper.

Herein lies the secret of the ancient Greek way of thinking and being conscious: in comparison with the irrational and impulsive temper of other modern peoples and societies, the temper of the ancient Greek, guided by his accounting formed a type of man who Aristotle called it magnanimity. This type of man, the so-called man who is usually called Man, was born in Ancient Greece and formed a civilization that revolutionized the History of Mankind and changed the course of History, he himself was not a model over time and intercultural.

That being said full suggestion of a "tripartite presentation" to "Existential" Human Being can also be found in sciencebased studies in Psychology and in the works of such highly-regarded men-of-letters as William Shakespeare and Ralph Waldo Emerson.

Pythagoras

Pythagoras lived in even earlier times of Ancient Greece than Socrates or Plato. Nevertheless, he advanced a similar Tripartite view of human nature to that suggested in Socratic Dialogues in Plato's widely influential works.

Desireous and Wrathfulful impulses presumably tend to arise, (according to circumstances?), from Human Nature and the World Religions are probably not wrong in advising us that following them inappropriately, and inadvisably, could lead us away from "the straight and narrow" path of (relative) righteousness.

Science (i.e. Psychology) 
Scientific studies can also be held to have identified a Tripartite Soul Theory-related presentation of Human Nature.

\section{World Religions}

The FIVE World Religions which have the most adherents, (Christianity, Islam, Hinduism, Buddhism and Sikhism), represent Spirituality - as being "relative" - to "Desire" and to "Wrath". On this basis it is surely not entirely unreasonable to suggest that Spirituality, tendencies toward experiencing Desires, and potentialities for Wraths, are all present, to some degree or other, in innate Human Nature.

The World Faiths tend to exhort us to follow courses of Spirituality and Holiness - rather than of Desire, or of Wrath.

Desireous and Wrathfulful impulses presumably tend to arise, (according to circumstances?), from Human Nature and the World Religions are probably not wrong in advising us that following them inappropriately, and inadvisably, could lead us away from "the straight and narrow" path of (relative) righteousness.

Christianity and FOUR MORE World Religions

Teachings can be identified in the texts of such World Religions as Christianity, Islam, Hinduism, Buddhism and Sikhism which can be seen as being accepting of a "Tripartism" to existential Human Being.

That is to say that there are indications in the teachings of each of these Major World Religions that "Spirituality" can be regarded as being Relative - to "Desire", and to "Wrath".

This Interfaith agreement can surely be taken as tending to contribute significant justification to an acceptance that highly important truths are to be associated with Tripartite Soul Theory.

This Interfaith agreement can surely be taken as tending to contribute significant justification to an acceptance that highly important truths are to be associated with Tripartite Soul Theory.

A highly important Christian teaching - The Parable of the Sower - will now be considered:

This "Parable of the Sower" could be said to suggest that Enlightenment does not appear to be Intellectual but may principally arise from keeping to spiritual teachings!!!
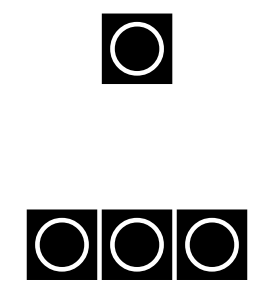

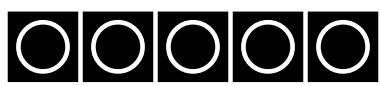

\section{0}

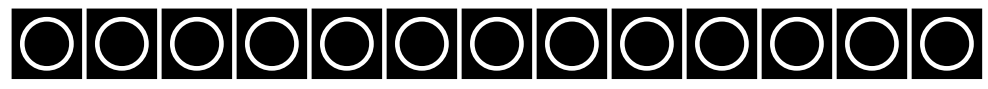


Leonidas A. Papakonstantinidis

Forming the Bargaining Win-Win-Win Papakonstantinidis Tripartite Focal Points Analysis of the Bibliography

Research on re-hierarchizing priorities, due to the pandemic

The study has been conducted to different samples (rural and urban) seven rural and seven urban areas of Peloponnese from 2021-01-01 till 2021-01-31.

Table 3: Examined urban areas

\begin{tabular}{|l|l|}
\hline & Urban Areas \\
\hline 1 & Tripoli \\
\hline 2 & Sparti \\
\hline 3 & Nafplio \\
\hline 4 & Patra \\
\hline 5 & Arcadia \\
\hline 6 & Egio \\
\hline 7 & Kalamata \\
\hline
\end{tabular}

Table 4: $\mathrm{A}_{1}$ SEXES 'GROUP

\begin{tabular}{|l|l|l|}
\hline MEN & WOMEN & total \\
\hline 199 & 301 & 500 \\
\hline
\end{tabular}

Table 5: A 2, AGE GROUP

\begin{tabular}{|c|l|l|}
\hline AGE GROUP & Men & Women \\
\hline $35-44$ years old & 25 & 40 \\
\hline $45-54$ years old & 34 & 41 \\
\hline $55-64$ years old & 40 & 110 \\
\hline $65-74$ years old & 65 & 72 \\
\hline $75+\quad$ total & 35 & 38 \\
\hline
\end{tabular}

Table 6: $\mathrm{A}_{3}$ EDUCATIONAL LEVEL

\begin{tabular}{|l|l|l|l|}
\hline & EDUC LEVEL & MEN & WOMEN \\
\hline 1 & PRIMARY & 39 & 108 \\
\hline 2 & HIGH & 102 & 142 \\
\hline 3 & UN. DEGREE & 47 & 51 \\
\hline 5 & SPECIFICATION & 10 & - \\
\hline 6 & PH.D & 1 & - \\
\hline 7 & POSTDOCTORAL & - & - \\
\hline
\end{tabular}


Leonidas A. Papakonstantinidis

Table 7: Questionnaire: Close Ended Questions

\begin{tabular}{|l|l|l|l|l|l|}
\hline & \multicolumn{3}{|c|}{ Intensity } \\
\cline { 2 - 5 } & Strongly & Disagree & Neutral & Agree & Strongly agree \\
\hline $\begin{array}{l}\text { Does the } \\
\text { pandemic affect } \\
\text { your values and } \\
\text { habits? }\end{array}$ & & & & & \\
\hline $\begin{array}{l}\text { Does the } \\
\text { pandemic affect } \\
\text { your } \\
\text { psychology? }\end{array}$ & & & & & \\
\hline $\begin{array}{l}\text { Do you feel } \\
\text { closer to other } \\
\text { people due to } \\
\text { pandemic? }\end{array}$ & & & & & \\
\hline
\end{tabular}

Table 8: Observed frequencies

\begin{tabular}{|c|c|c|c|c|c|c|}
\hline & \multicolumn{5}{|c|}{ Intensity } & \multirow[b]{2}{*}{ Column total } \\
\hline & $\begin{array}{l}\text { Strongly } \\
\text { disagree }\end{array}$ & Disagree & Neutral & Agree & $\begin{array}{l}\text { Strongly } \\
\text { agree }\end{array}$ & \\
\hline $\begin{array}{l}\text { Does the } \\
\text { pandemic } \\
\text { affect your } \\
\text { values and } \\
\text { habits? }\end{array}$ & 13 & 15 & 11 & 75 & 61 & 175 \\
\hline $\begin{array}{l}\text { Does the } \\
\text { pandemic } \\
\text { affect your } \\
\text { psychology? }\end{array}$ & 17 & 40 & 20 & 50 & 11 & 138 \\
\hline $\begin{array}{l}\text { Do you feel } \\
\text { closer to } \\
\text { other people } \\
\text { due to } \\
\text { pandemic? }\end{array}$ & 28 & 27 & 17 & 54 & 61 & 187 \\
\hline Row total & 58 & 82 & 48 & 179 & 133 & 500 \\
\hline
\end{tabular}




\section{$\mathrm{E}=\underline{\text { (row..total })(\text { column..to tal })}$ grand..tot al}

Table 9: Expected frequencies

\begin{tabular}{|c|c|c|c|c|c|}
\hline & \multicolumn{5}{|c|}{ intensity } \\
\cline { 2 - 6 } & $\begin{array}{c}\text { Strongly } \\
\text { disagree }\end{array}$ & Disagree & Neutral & Agree & Strongly agree \\
\hline $\begin{array}{c}\text { Does the } \\
\text { pandemic } \\
\text { affect your } \\
\text { values and } \\
\text { habits? }\end{array}$ & 20,3 & 28,7 & 16,8 & 62,65 & 46,55 \\
\hline $\begin{array}{c}\text { Does } \\
\text { pandemic } \\
\text { affect your } \\
\text { psychology? }\end{array}$ & 16,0 & 22,6 & 13,3 & 49,04 & 36,7 \\
\hline $\begin{array}{c}\text { Do you feel } \\
\text { close to } \\
\text { other people } \\
\text { due to } \\
\text { pandemic? }\end{array}$ & 10,8 & 30,7 & 17,9 & 66,9 & \\
\hline
\end{tabular}

$$
\chi_{c}^{2}=\sum_{i=1}^{k} \frac{\left(o_{i}-E_{i}\right)^{2}}{E_{i}}
$$

Table 10: Pandemic Research Table

\begin{tabular}{|c|c|c|c|c|c|c|c|}
\hline & \multicolumn{5}{|c|}{ intensity } & & \\
\hline & $\begin{array}{l}\text { Strongly } \\
\text { disagree }\end{array}$ & Disagree & Neutral & Agree & $\begin{array}{c}\text { Strongly } \\
\text { agree }\end{array}$ & & \\
\hline $\begin{array}{l}\text { Does the } \\
\text { pandemic } \\
\text { affect your } \\
\text { values and } \\
\text { habits? }\end{array}$ & $\begin{array}{c}20,3-13 \\
(7,3)^{\wedge} 2 \\
0,9\end{array}$ & $\begin{array}{c}28,7-15 \\
(13,7)^{\wedge} 2 \\
6,53\end{array}$ & $\begin{array}{c}16,8-11 \\
(5,8)^{\wedge} 2 \\
2,00\end{array}$ & $\begin{array}{c}75-62,65 \\
(12,35)^{\wedge} 2 \\
2,43\end{array}$ & $\begin{array}{c}61-46,55 \\
(14,45)^{\wedge} 2 \\
4,48\end{array}$ & $\underline{16,34}>15,507$ & $\mathrm{H}_{0}$ \\
\hline $\begin{array}{c}\text { Does } \\
\text { pandemic } \\
\text { affect your } \\
\text { psychology? }\end{array}$ & $\begin{array}{c}17-16,0 \\
(1)^{\wedge} 2 \\
0,06\end{array}$ & $\begin{array}{c}40-22,6 \\
(17,3)^{\wedge} 2 \\
13,3\end{array}$ & $\begin{array}{c}20-13,3 \\
(6,7)^{\wedge} 2 \\
3,4\end{array}$ & $\begin{array}{c}50-49,04 \\
(0,6)^{\wedge} 2 \\
0,007\end{array}$ & $\begin{array}{c}36,7-11 \\
(25,7)^{\wedge} 2 \\
17,99\end{array}$ & $\underline{34,82>15,507}$ & $\mathrm{H}_{0}$ \\
\hline $\begin{array}{c}\text { Do you feel } \\
\text { close to } \\
\text { other people } \\
\text { due to } \\
\text { pandemic? }\end{array}$ & $\begin{array}{c}28-10,8 \\
(17,2)^{\wedge} 2 \\
27,39\end{array}$ & $\begin{array}{c}24-30,7 \\
(6,7)^{\wedge} 2 \\
1,46\end{array}$ & $\begin{array}{c}20-17,9 \\
(2,04)^{\wedge} 2 \\
0,2\end{array}$ & $\begin{array}{c}74-66,9 \\
(7,0)^{\wedge} 2 \\
0,7\end{array}$ & $\begin{array}{c}61-49,7 \\
(11,3)^{\wedge} 2 \\
0,03\end{array}$ & $\underline{29,78}>15,507$ & $\mathrm{H}_{0}$ \\
\hline
\end{tabular}


a : level..of.significance...usually,...0,05

df $=\mathrm{v}: . .($ rows -1$)($ columne $\mathrm{s}-1)$

de.grees..of ...freedom,...(df)

$d f=(R-1) \times(C-1)$

We calculate the degrees of freedom (df). $c=$ de.grees..of ...freedom,...(df)

$d f=(R-1) \times(C-1)$

Then, the number of $d f_{\text {is equal to }} d f=(R-1) \times(C-1)$

Here $d f_{=(3-1)(5-1)=8}$

Note: Any question is independent of the intensity of the answers

$E_{k}, .1, . .2 \ldots k$ are the corresponding expected frequencies based on the null hypothesis, $H_{0}$

The $\chi^{2}$ with which we do such a case test is called $\chi^{2}$ control of good fit.

In this section we will also get to know our $\chi^{2}$ independence test allows us to respond to problems such as the following, which relate to control of the independence of two characteristics / variables.

\section{cases}

A. The null hypothesis $\mathrm{H}_{0}$ The frequencies of the three types of study are not different between them (bilateral control).

$\chi_{n}^{2}=\sum_{i=1}^{k} \frac{\left(O_{i}-E_{i}\right)^{2}}{E_{i}} \succ \chi_{\kappa-1, a}^{2}$

B. Alternative hypothesis: The frequencies of the three types of study are different between them

$\chi_{n}^{2}=\sum_{i=1}^{k} \frac{\left(O_{i}-E_{i}\right)^{2}}{E_{i}} \prec \chi_{\kappa-1, a}^{2}$

${ }^{2}$ degrees of freedom 


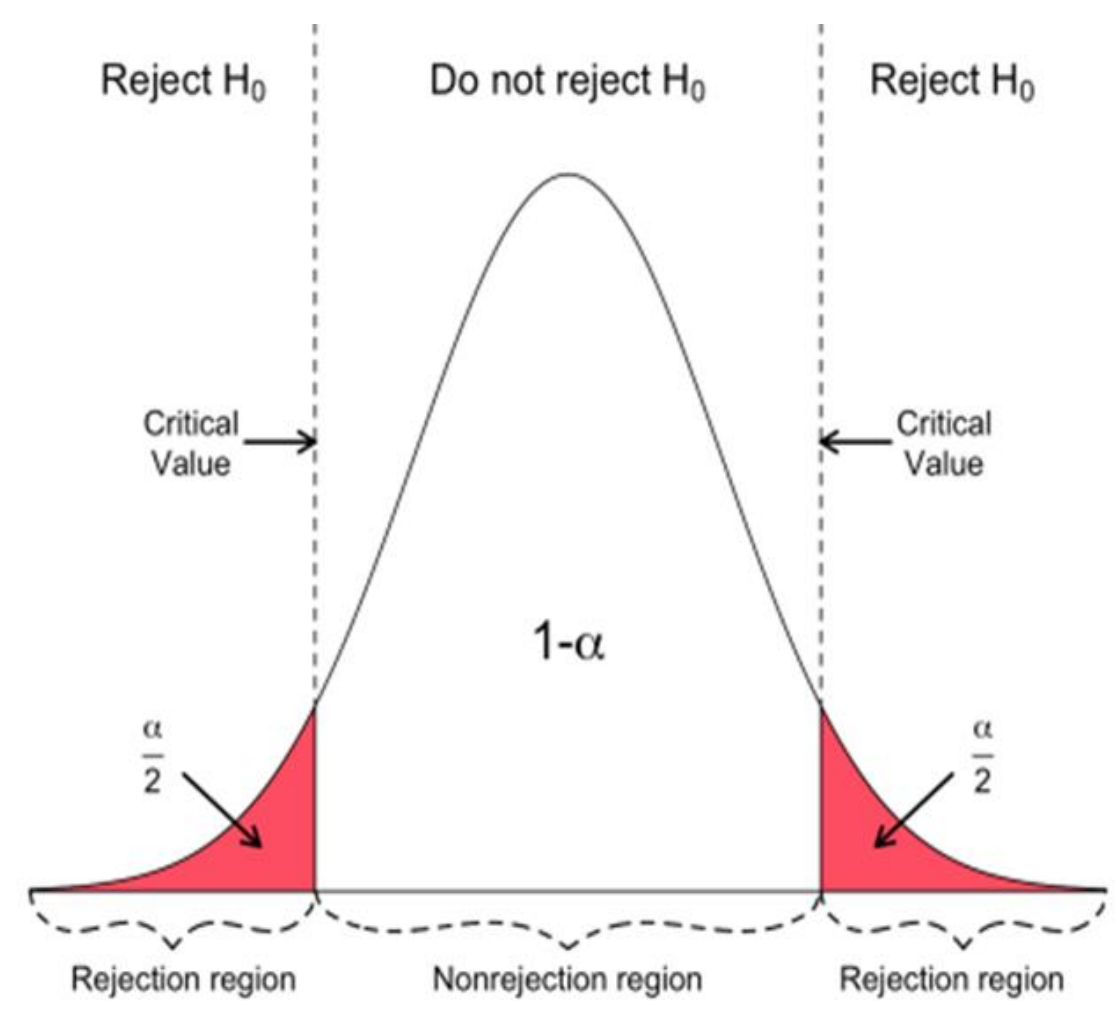

Figure 9: Alternative hypothesis

Table 11: Critical values of the Chi-square distribution with d degrees of freedom

\section{Critical values of the Chi-square distribution with $d$ degrees of freedom}

\begin{tabular}{|c|c|c|c|c|c|c|c|}
\hline \multirow[b]{2}{*}{$d$} & \multicolumn{7}{|c|}{ Probability of exceeding the critical value } \\
\hline & 0.05 & 0.01 & 0.001 & $d$ & 0.05 & 0.01 & 0.001 \\
\hline 1 & 3.841 & 6.635 & 10.828 & 11 & 19.675 & 24.725 & 31.264 \\
\hline 2 & 5.991 & 9.210 & 13.816 & 12 & 21.026 & 26.217 & 32.910 \\
\hline 3 & 7.815 & 11.345 & 16.266 & 13 & 22.362 & 27.688 & 34.528 \\
\hline 4 & 9.488 & 13.277 & 18.467 & 14 & 23.685 & 29.141 & 36.123 \\
\hline 5 & 11.070 & 15.086 & 20.515 & 15 & 24.996 & 30.578 & 37.697 \\
\hline 6 & 12.592 & 16.812 & 22.458 & 16 & 26.296 & 32.000 & 39.252 \\
\hline 7 & 14.067 & 18.475 & 24.322 & 17 & 27.587 & 33.409 & 40.790 \\
\hline 8 & 15.507 & 20.090 & 26.125 & 18 & 28.869 & 34.805 & 42.312 \\
\hline 9 & 16.919 & 21.666 & 27.877 & 19 & 30.144 & 36.191 & 43.820 \\
\hline 10 & 18.307 & 23.209 & 29.588 & 20 & 31.410 & 37.566 & 45.315 \\
\hline
\end{tabular}

The answers -frequencies to all the questions are better adapted (test of good adaptation) to the expected That is, the observed frequencies of all the variables are adapted to the expected and the assumption is true Also, all the answersfrequencies in the following multivariate are independent of each other.

Table 11: Opinion types on research questions

\begin{tabular}{|l|l|l|l|l|}
\hline I strongly disagree & Disagree & Neutral & Agree & I strongly agree \\
& & & \\
\hline
\end{tabular}


Finally, we can - in theory - take as large a sample of observations as possible and the Zero Hypothesis be true. Even further, in some hypothetical situation the observed frequencies may be identical to the expected.

\section{olololololololo}

\section{References}

- Ignacio Ramonet, (1996). Nouveaux pouvoirs, nouveaux maîtres du monde. New Powers, New World Masters.

- Gold, N., \& Sugden, R (2006). Beyond individual choice: Teams and frames in game theory. Princeton University Press, Princeton, NJ.

- Jonathan W. Leland \& Mark Schneider (2018). A Theory of Focal Points in 2x2 Games. Economic Science Institute. CrossRef

- $\quad$ Ken B., Joe S., Steven H., \& Christ P., (1993). Focal Points and Bargaining. International Journal of Game Theory. CrossRef

- Lambros Iossif-Leonidas A. Papakonstantinidis (1990). Observation on a Limit. Mathematical Review.

- Leland, J., \& Schneider, M., (2018). A theory of focal points in 2x2 games. Journal of Economic Psychology. CrossRef

- Mehta, J., Starmer, Ch., Sugden, R., (1994). The Nature of Salience: An Experimental Investigation of Pure Coordination Games. The American Economic Review.

- Papakonstantinidis, L., A., (2002). the win-win-win model. Euracademy guide.

- Papakonstantinidis, L., A., Steps towards Democracy: 3-person rationality, A win-win-win papakonstantinidis approach-collection of the literature.

- Schelling, Thomas C., (1960). The strategy of conflict (First ed.). Cambridge: Harvard University Press.

Schelling, Thomas C., (1960). The strategy of conflict (First ed.). Cambridge: Harvard University Press 